\title{
Retrato de uma ausência: a mídia nos relatos da história política do Brasil
}

\author{
Luis Felipe Miguel
}

Universidade de Brasília

RESUMO

Nos últimos 50 anos, consolidou-se no Brasil uma moderna indústria da comunicação de massas, que é o principal veículo de informação (e entretenimento) de dezenas de milhões de pessoas. Além do impacto cumulativo a longo prazo sobre as representações de mundo de seus consumidores, a mídia foi partícipe direta e importante de episódios de nossa história política. No entanto, as narrativas do período mal tocam nos meios de comunicação. 0 presente trabalho analisa esta ausência (nas obras de autores como Skidmore, Costa Couto e Fausto) e discute porque historiadores e cientistas políticos ainda se sentem desconfortáveis com a influência política da mídia.

Palavras-chave: Meios de Comunicação; História Política do Brasil; Democracia; mídia.

\begin{abstract}
In the last 50 years, a modern communication industry has consolidated itself in Brazil. It provides tens of millions of people with information and entertainment. The media have cumulative, long-term impact on their consumers' worldviews, but also had important direct participation in events of recent Brazilian political History. However, the accounts of the period scarcely touch the media. This article analyses such absence (in the works of authors as Skidmore, Costa Couto, and Fausto) and examines why historians and political scientists still feel uncomfortable with the political influence of the media.

Keywords: Media; Brazilian Political History; Democracy; media.
\end{abstract}


Tornou-se lugar-comum dizer que, em nossas sociedades, a mídia é quase onipresente. Somos bombardeados por ela. Só nos últimos 30 anos, a humanidade produziu mais informações do que nos cinco milênios precedentes. Os meios de comunicação alteraram nossa maneira de ver o mundo que nos cerca - um mundo, aliás, que eles ampliaram brutalmente, tanto por meio dos fatos que o jornalismo transmite quanto da experiência vicária proporcionada pelas diferentes formas de arte e entretenimento. 0 meio dominante (a televisão), em especial, transformou a vida cotidiana, incluindo aspectos tão básicos quanto a gestão do tempo e do espaço (doméstico ou social).

A mídia, categoria ampla e em permanente mutação, que inclui a TV aberta e por assinatura, rádio, jornais, revistas, cinema, indústria fonográfica, internet etc, tornou-se parte integrante da vida dos homens e mulheres contemporâneos - e é um de seus companheiros mais freqüentes. Dados relativos aos Estados Unidos dizem que, em média, cada adulto dedica quase seis horas e meia diárias de atenção à mídia, contra cerca de 14 minutos para a interação interpessoal familiar. No mundo todo, nas sociedades urbanas, o consumo de mídia é uma das duas maiores categorias de atividade, atrás apenas do trabalho. Mas o dispêndio de tem192 po no trabalho está em declínio, enquanto que, para a mídia, a tendência é oposta.

Nada parece resistir aos meios de comunicação de massa. Ou melhor, quase nada. Não quero dizer, como nas aventuras de Astérix, que os livros de história política do Brasil são a "última aldeia gaulesa" que resiste à influência dos meios, até porque não se trata de resistir a ela, mas de negar tal influência. É notável a maneira pela qual os relatos da nossa história política ignoram, via de regra, a existência da mídia e seu impacto social.

Este artigo possui ambições bastante modestas. Desejo, em primeiro lugar, evidenciar a quase completa ausência da mídia nas narrativas da história política do Brasil, do peńodo de 1930 para cá, ao mesmo tempo indicando porque esta ausência é relevante (ou, o que dá na mesma, porque a presença dos meios de comunicação é importante para se compreender a política). Em seguida,indicarei algumas das possíveis causas desta ausência.

Vou me limitar a obras de caráter mais factual, já que os esforços analíticos podem, justificadamente, privilegiar alguns aspectos em detrimento de outros, obliterando assim, por exemplo, a influência da mídia. E estou referindo-me apenas a livros de história política, já que a história 
cultural, dos costumes, das mentalidades etc tem sido muito mais sensível aos efeitos dos meios de comunicação na sociedade.

Para evidenciar tal ausência, escolhi quatro livros que estão entre os mais adotados no ambiente acadêmico: Em primeiro lugar, os dois principais livros do brazilianista norte-americano Thomas Skidmore, Brasil: de Getúlio a Castelo ${ }^{1}$ e Brasil: de Castelo a Tancredo ${ }^{2}$, trabalhos sem maior ambição interpretativa, mas muito bem documentadas e que formam, em conjunto, provavelmente a mais lida narrativa da história política do Brasil entre 1930 e 1985.

Depois, o livro de Boris Fausto, História do Brasil ${ }^{3}$. Trata-se de um manual voltado para o ensino médio e universitário, com a intenção de prover uma informação mais aprofundada do que a fornecida pelos livros-texto tradicionais. A obra parte das civilizações pré-colombianas no Brasil, mas, para os fins deste artigo, interessa apenas o período iniciado pela Revolução de 30.

E, por fim, o livro de Ronaldo Costa Couto, História indiscreta da ditadura e da abertura ${ }^{4}, 0$ mais recente de todos. Como o título já indica, a obra - nascida de uma tese de doutoramento - trata apenas do período entre 1964 e 1985. É um exercício de inside History, já que o autor exerceu cargos político-administrativos durante o regime militar, em seguida tornou-se íntimo colaborador do líder oposicionista Tancredo Neves e chegou a ministro de Estado na presidência de José Sarney. Assim, seu relato é alimentado pelo conhecimento direto dos bastidores políticos e, ainda mais, pelos depoimentos inéditos que obteve de vánios protagonistas.

Os quatro títulos mencionados não formam, é evidente, uma relação exaustiva, que seria inviável diante dos estreitos limites deste trabalho, mas, creio, são suficientemente representativos. São livros com ambições diferentes, embora todos considerados, pela comunidade acadêmica, como obras historiográficas ao mesmo tempo "sérias" (merecedoras do respeito intelectual dos confrades) e "acessíveis" ao leitor nãoespecializado (tendo, por isso, impacto na formação de estudantes).

PRESENÇA ESVAZIADA

Demonstrar uma ausência, que é o que pretendo fazer aqui, é algo meio bizarro: é falar do que não é, do que não está. É mais fácil (e útil) apontar episódios nos quais os meios de comunicação exerceram papel significativo e apontar como esta presença é esvaziada. Mas antes, à guisa de ilustração, vale fazer uma contagem de referências à mídia num li- 
vro. Escolhi a História do Brasil , de Boris Fausto, mas os números para qualquer um dos outros seriam muito semelhantes.

No livro de Fausto, em cerca de 250 páginas, que cobrem o período entre 1930 e 1989, as referências aos meios de comunicação mal passam de uma dúzia (para ser exato, são 15). E sempre, sem exceção, são secundárias ou anedóticas: a sede do jornal O Globoé depredada após o suicídio de Getúlio, há uma referência lateral a um quadro do humorista Jô Soares na televisão e assim por diante. O poderoso DIP, instrumento de propaganda do Estado Novo, é lembrado em apenas um parágrafo; a Rede Globo também merece uma única citação, em que se reconhece seu papel na legitimação da ditadura de 645. Mas quando faz um capítulo de síntese sobre as "Principais mudanças ocorridas no Brasil entre 1950 e 1980", a extraordinária difusão da mídia nem sequer é lembrada ${ }^{6}$. $\mathrm{a}$ adjetivo "extraordinária" nada tem de exagero: 1950 é o ano zero da TV no Brasil; em 1980, 56,1\% dos domicílios brasileiros já possuíam ao menos um televisor, número que chegaria a 71\% em 1991.

Há uma última evidência do menosprezo à mídia no livro de Boris Fausto. Num apêndice com notas biográficas so bre cerca de 400 personalidades, os empresários Assis Chateaubriand e Roberto Marinho (donos, respectivamente, dos Diários Associados e da Rede Globo) estão ausentes - embora sejam incluídas figuras relativamente pouco importantes, como os deputados Odilon Braga e Francisco Morato ou o senador Carlos de Campos ${ }^{7}$.

Mas o impacto da mídia neste período é incontornável. Às vezes, exatamente por estarmos tão imersos em nosso mundo mediatizado, nem nos damos conta das múltiplas conseqüências sociais da presença dos meios de comunicação. O jornal diário, o rádio e, sobretudo, a televisão impõem-se como os instrumentos por excelência da mediação entre seus leitores, ouvintes e espectadores e a realidade circundante. A mídia estrutura novos padrões de ordenação do tempo ("antes do telejornal", "depois da novela") e mesmo do espaço (basta pensar na presença do televisor como objeto dominante na maior parte das salas de estar). Por meio da programação jornalística e de entretenimento, ela transforma, ou amplia, o fluxo de informações entre setores antes relativamente estanques da sociedade, com impacto significativo nas relações entre os gêneros, entre as faixas etárias, e também nas formas da atividade política8.

As novas informações a que os indivíduos têm acesso (e a partir das quais vão se situar no mundo) são filtradas pelos meios de comunicação. Na qualidade de sistemas especializados de busca, organização e distri- 
buição de informações, os órgãos jornalísticos cumprem uma tarefa indispensável à vida das sociedades contemporâneas. Ao mesmo tempo, colocam a esmagadora maioria dos cidadãos na condição de consumidora de informações, dependente do material que recebe da mídia e constrangida à crença na acurácia do trabalho de seus fornecedores ${ }^{9}$.

\section{A MÍDIA NO BRASIL, DESDE 1930}

O período de 1930 para cá é de acelerada e ininterrupta expansão da mídia no Brasil. Dois processos são cruciais: a formação dos Diários Associados, que tem início na década de 20 e atinge seu ápice no final dos anos 50, e a da Rede Globo, após o golpe de 1964. Cada um a seu tempo e com os instrumentos de que dispunham na época (rede de jornais, revistas e rádio ou rede de televisão), ambos são vetores fundamentais do processo de integração nacional. Ainda no início da construção do império Diários Associados de Assis Chateaubriand, seu projeto era visto pelos líderes políticos da época, a começar pelo deputado federal Getúlio Vargas, como ferramenta da união nacional ${ }^{10}$. Quando, em setembro de 1969, estréia o primeiro telejornal transmitido simultaneamente de Norte a Sul do País (o Jornal Nacional ), o processo está próximo de sua conclusão.

A transformação na organização do cotidiano e a "integração nacional" são efeitos cumulativos de longo prazo, com impacto profundo nas diversas esferas da vida social, aí incluída também a política em seu sentido mais restrito. No entanto, os livros analisados concedem pouquíssimo espaço (quando concedem) a estes acontecimentos - e nunca buscam conectá-los com a emergência de novas formas de ação política.

Além desses efeitos de longo prazo, a mídia também teve participação direta importante em momentos específicos da política nacional. Na deflagração da Revolução de 30, por exemplo, Assis Chateaubriand desempenhou um papel destacado. O jo rnalista ajudou a convencer Antônio Carlos, o governador de Minas Gerais, a apoiar Getúlio Vargas. Mais importante, colocou sua cadeia de jornais (e a importante revista O Cru zeiro) a serviço da Aliança Liberal. Teve papel decisivo na dramatização e amplificação do assassinato de João Pessoa, criando o clima de opinião favorável ao movimento revolucionário. No entanto, Boris Fausto e Thomas Skidmore nem sequer o citam ao narrar o episódio. O obelisco da Avenida Rio Branco, no Rio de Janeiro, onde os gaúchos amarraram seus cavalos, é considerado parte significativa da história. A imprensa que fez 
da foto dos cavalos no obelisco um emblema da nova ordem política nacional não merece ser citada.

A figura de Chateaubriand, aliás, é apagada da história do Brasil por inteiro, no caso do livro de Boris Fausto, ou quase, como no relato de Skidmore ${ }^{11}$. No entanto, respaldado por sua rede de comunicação, ele apoiava revoluções (como a de 30 e a Constitucionalista), influenciava o resultado de eleições, exercia poder de veto sobre a composição de ministérios, arrancava reformas na legislação; por duas vezes, forçou renúncias de parlamentares para conseguir se eleger senador; impôs a si pró prio como embaixador do Brasil em Londres. Na fórmula feliz de Bemardo Kucinski, Chateaubriand e os outros barõ es da imprensa da época eram "chantagistas que se imiscuíam no jogo regular de poder das elites dominantes" ${ }^{12}$. Extirpar tal chantagem da história política brasileira é deformar sua representação.

E há também a instrumentalização da mídia por parte do poder. A ação do Departamento de Imprensa e Propaganda (DIP) durante o Estado Novo não foi algo secundário na arquitetura do regime. Foi fundamental para a sua legitimação e estabilidade; mais do que isso, está na raiz do mito criado em torno de Getúlio Vargas, que permaneceu atuante depois da redemocratização e, mesmo, após a morte do caudilho.

Mais significativa ainda é a atuação da mídia, em especial da Rede Globo, durante o regime militar - uma espécie de DIP privado, justamente por isso com maior legitimidade. Embora um estudo mais aprofundado ainda esteja para ser feito, é bastante plausível afirmar que as telenovelas da Globo desempenharam um papel crucial na difusão do mito do milagre brasileiro. Símbolo "vivo" da prosperidade doméstica, o televisor, que passou a estar presente em milhões de lares, mostrava em sua telinha a imagem da prosperidade nacional.

Também é notável a maneira pela qual as obras em foco ignoram a influência da mídia sobre os processos eleitorais. Os jornais, primeiro, e o rádio e a televisão, depois, tornaram-se os principais vetores da imagem pública dos candidatos, com impacto significativo, portanto, sobre seu desempenho nas urnas. Ou mesmo fora delas, como foi o caso da eleição indireta de 1985. Em seu livro, Ronaldo Costa Couto anota, sem maior destaque, o apoio de Roberto Marinho e outros donos de meios de comunicação a Tancredo Neves; mas depois deixa transparecer que a Rede Globo colocou-se a serviço do candidato da Aliança Democrática para gerar o clima de opinião propício. As ações públicas dos líderes alian- 
cistas eram acertadas previamente com a emissora, que garantia a cobertura mais ampla ${ }^{13}$.

O caso mais evidente do influxo dos meios de comunicação sobre uma eleição é a vitória de Collor, em 1989, que foge do período compreendido pelos quatro livros escolhidos. Collor se projetou como liderança política de envergadura nacional usando uma estratégia de exposição à mídia; o apoio da Rede Globo alavancou sua candidatura; a telenovela de maior sucesso na época, Que rei sou eu?, alimentou a idéia de que só alguém estranho ao establishment político, como Collor dizia ser, poderia salvar o país; a edição do último debate da campanha eleitoral no Jornal Nacional foi, segundo algumas análises, decisiva para sua vitória no segundo turno.

Mas o caso de Collor é o mais notável pelo destaque da mídia também em seu impeachment. A imprensa teve um papel essencial no processo, em especial as revistas Veja e IstoÉ. Na visão de Bernardo Kucinski, elas agiram como representantes de seu leitorado, as classes médias urbanas, que apoiaram Collor, mas se sentiram logradas com o confisco da poupança ${ }^{14}$. A hipótese precisaria ser confirmada; ela deixa subentendido - e isto é importante - que a mídia não se limita a amplificar iniciativas da elite política, mas age muitas vezes de maneira autônoma na arena política.

\section{RAZÕES DA AUSÊNCIA}

Num livro clássico de 1922, Public opinion, Walter Lippmann lamentava o fato de que "a ciência política é ensinada nas faculdades como se os jornais não existissem" ${ }^{\prime 1}$. Q uase 80 anos depois, pouca coisa mudou. Em parte, isto talvez possa ser explicado pelos hábitos de pensamento herdados por cientistas e historiadores políticos, acostumados a ver 0 campo da política to mado apenas por partidos, governos, forças armadas, igreja e, quando muito, sindicatos - ou seja, a política dos séculos 17 a 19, quando os meios de comunicação ainda engatinhavam.

Mais relevante, porém, parece ser o elitismo que subjaz à au sência da mídia. Nas sociedades formalmente democráticas em que vivemos, é corrente a divisão da política em bastidores, as salas secretas em que se fazem os acordos e se tomam as grandes decisões, e palco, o jogo de cena representado para os não-iniciados, isto é, para o povo em geral. 0 que ocorre no palco serviria apenas para distrair a platéia e manter a estabilidade do sistema, perpetuando o mito da democracia como "governo do povo". Por motivos óbvios, a mídia pertence a este segundo espa- 
ço - mas os fatos políticos relevantes ocorreriam no primeiro, nos bastidores.

Não se trata de negar as imperfeições da democracia formal, que se caracteriza, de fato, pela limitação da participação política popular. Mas a distinção entre bastidores e palco merece ser relativizada por, no mínimo, quatro fatores:

1) longe de ser um dado "da natureza", como quer a tradição do pensamento elitista (de Mosca, Pareto, Schumpeter e seus muitos seguidores atuais), a passividade política da "massa" precisa ser produzida. Aliás, uma investigação sobre o papel dos meios de comunicação na produção desta passividade seria de grande interesse;

2) nem sempre a "massa" se mantém passiva. Pelo contrário, ela irrompe, de tempos em tempos no jogo político - a platéia invade o palco e tumultua aquilo que fora acertado nos bastidores;

3) nos regimes formalmente democráticos, o povo mantém a prerrogativa de decidir quem exercerá o poder político. Ou, continuando com a metáfora, a platéia decide quem vai para os bastidores, e em qual posição (ou ao menos controla parte da decisão, já que os grandes patrões e os chefes militares, por exemplo, influenciam a política sem se submeterem ao crivo das eleições). Alguns autores reduzem o processo eleitoral a um ritual de coesão social, desprovido de conseqüências práticas, mas o argumento não se sustenta. É difícil sustentar que votar em Hitler, em vez de nos sociais-democratas, nos comunistas ou na direita tradicional, na Alemanha de 1933, não tinha conseqüências importantes. Ou em Salvador Allende, no Chile em 1970. Ou, tomand o um exemplo menos dramático, que a vitória de Lula, e não de Collor, em 1989, não representaria um curso diferente para a história imediata do Brasil;

4) mas não é só no momento eleitoral que a voz da platéia se faz ouvir.

O público não é indiferente ao que ocorre nos bastidores, nem estes são impermeáveis à sua curio sidade. Muitas vezes, uma "revelação" dos bastidores é um momento crucial do jogo político - Watergate e o impeach ment de Collor são dois exemplos óbvios.

O que os elitistas apontam como natural - a desigualdade política, a profunda divisão entre governantes e governados - é fruto de uma organização social que concentra em poucas mãos o capital político ${ }^{16}$. Alguns poucos monopolizam a capacidade de intervir no campo político - exatamente porque os outros internalizam a própria impotência e oferecem o reconhecimento de que aqueles poucos são os "líderes". Se o re- 
conhecimento so cial é a chave da conquista do capital político, avulta a importância da mídia, principal difusora do prestígio e do reconhecimento social nas sociedades contemporâneas.

\section{NOTAS}

${ }^{1}$ SKID MORE, Thomas. Brasil: de Getúlio a Castelo. Rio de Janeiro, Paz e Terra, 1982. A edição original é de 1966.

${ }^{2}$ SKIDMORE, Thomas. Brasil: de Castelo a Tancredo . Rio de Janeiro, Paz e Terra, 1988.

${ }^{3}$ FAUSTO, Boris. História do Brasil . São Paulo, Edusp, 1994.

${ }^{4}$ COUTO, Ronaldo Costa. História indiscreta da ditadura e da abertura . Rio de Janeiro, Record, 1998.

${ }^{5}$ Ver FAUSTO. op. cit., pp. 418, 502, 376 e 484.

${ }^{6}$ Idem, pp. 529-550.

${ }^{7}$ Idem., pp. 597-640.

${ }^{8}$ Ver MEYROWITZ, Joshua. No sense of place Oxford, Oxford University Press, 1985.

${ }^{9}$ MIGUEL, Luis Felipe. “O jornalismo como 'sistema perito'”. In Tempo Social São Paulo, FFLCH-USP, 1999, vol. 11, nº 1, pp. 197-208.

${ }^{10}$ MORAIS, Fernando. Chatô: o rei do Brasil . São Paulo, Companhia das Letras, 1994, p. 145.

${ }^{11}$ Chateaubriand é citado apenas quatro vezes, e sempre en passant, em Brasil: de Getúlio a Castelo .

${ }^{12}$ KUCINSKI, Bernardo. A síndrome da antena parabólica . São Paulo, Fundação Perseu Abramo, 1998, p. 167.

${ }^{13}$ Ver o depoimento de Antônio Carlos Magalhães em COUTO. op. cit., p. 378.

${ }^{14}$ KUCINSKI. op. cit., p. 172.

${ }^{15}$ LIPPMANN, Walter. Public opinion. New York, Free Press, 1997, p. 203.

${ }^{16}$ Ver, BOURDIEU, Pierre. La distinction: critique sociale du jugement . Paris, Minuit, 1979.

Artigo recebido em 11/1999. Aprovado em 01/2000. 